\title{
PEMODELAN HUBUNGAN ANTARA KESEJAHTERAAN HIDUP, KESERAKANAN, DAN KESEJAHTERAAN DI TEMPAT KERJA DENGAN EFIKASI GURU SECARA KOLEKTIF
}

\author{
(MODELLING THE RELATIONSHIPS BETWEEN \\ PERSONAL WELL-BEING, COLLEGIALITY, \\ WORKPLACE WELL-BEING AND \\ COLLECTIVE TEACHER EFFICACY)
}

\author{
${ }^{1}$ Yusni Zaini Yusof, ${ }^{2}$ Rosna Awang Hashim \& \\ ${ }^{3}$ Tengku Faekah Tengku Ariffin \\ 1,2\& 3Pusat Pengajian Pendidikan dan Bahasa Moden \\ Universiti Utara Malaysia \\ ${ }^{1}$ Corresponding author: yusnizaini@yahoo.com
}

\begin{abstract}
ABSTRAK
Tujuan - Berdasarkan model kognitif sosial, kajian ini mengkaji kesan langsung dan tidak langsung terhadap efikasi guru secara kolektif. Secara khusus, kajian ini menilai peranan kesejahteraan hidup, keserakanan, kesejahteraan di tempat kerja dalam menerangkan efikasi guru secara kolektif.
\end{abstract}

Metodologi - Seramai 836 sampel guru dipilih secara rawak dari dua belas buah MRSM Zon Timur di Malaysia. Data kajian ini diperolehi melalui soal selidik yang mengandungi 85 item. Data ini telah dianalisis dengan menggunakan statistik deskriptif dan Analisis Persamaan Berstruktur.

Dapatan - Dapatan kajian ini menunjukkan kesejahteraan hidup, keserakanan dan kesejahteraan di tempat kerja adalah secara signifikan mempengaruhi efikasi guru secara kolektif. Berdasarkan kepada penilaian keseluruhan model, didapati bahawa kesepadanan model adalah munasabah. Dapatan analisis persamaan berstruktur menunjukkan bahawa kesejahteraan di tempat kerja adalah pengantara separa hubungan kesejahteraan hidup guru, keserakanan 
guru dan efikasi guru secara kolektif. Berbanding kesejahteraan hidup, keserakanan guru memperlihatkan kesan yang lebih kuat terhadap efikasi guru secara kolektif.

Signifikan - Kajian ini memperkenalkan model yang menunjukkan kepentingan kesejahteraan hidup, keserakanan dan kesejahteraan di tempat kerja sebagai penyumbang yang signifikan kepada efikasi guru secara kolektif. Ia juga mengenal pasti kepentingan keserakanan guru dalam membangunkan efikasi guru secara kolektif.

Kata kunci - Kesejahteraan hidup, keserakanan, kesejahteraan di tempat kerja, efikasi guru secara kolektif.

\section{ABSTRACT}

Purpose - Based on a social cognitive model, the study examined direct and indirect precursors of collective teacher efficacy. Specifically, it assessed the roles of personal well-being, collegiality and workplace well-being to explain collective teacher efficacy.

Methodology - A sample of 836 teachers were randomly selected from twelve MRSM in the east coast of Malaysia. Data were obtained through a survey questionnaire that comprised 85 items and analysed using descriptive statistics and Structural Equation Modelling.

Findings - Results indicate that personal well-being, collegiality and workplace well-being significantly influence collective teacher efficacy. Based on the holistic approach in model evaluation, the overall measurement model and the structural model are found to be adequately fit. The findings of the structural equation modelling indicate that workplace well-being partially mediates the relationship of personal well-being, collegiality and collective teacher efficacy. Compared to personal well-being, teacher collegiality seems to exhibit a stronger impact on collective teacher efficacy.

Significance - The study proposes a model which highlights the importance of personal well-being, collegiality and work-place well-being as significant contributors to collective teacher efficacy. It also identifies the importance of teacher collegiality in developing collective teacher efficacy. 
Keywords - Personal well-being, collegiality, work place wellbeing, collective teacher efficacy.

\section{PENGENALAN}

Guru merupakan elemen terpenting dalam pedagogi untuk menghasilkan pendidikan yang berkualiti. Kualiti pengajaran guru pada hari ini atau masa-masa yang akan datang jika dibandingkan dengan hari-hari yang lepas adalah tidak sama atau sukar untuk dipiawaikan. Kesejahteraan guru di tempat kerja dan faktor-faktor yang menjejaskan kesejahteraan guru boleh mempengaruhi kualiti pengajaran guru dan seterusnya mempengaruhi pula produktiviti, prestasi dan kecekapan guru (Noriati A. Rashid, Boon Pong Ying, \&, Wong Kiet Wah, 2010). Kesejahteraan guru adalah berkait rapat dengan efikasi kerja. Kajian mendapati guru yang tidak menepati tahap efikasi kerja adalah lebih mudah untuk meninggalkan bidang perguruan (Pas, Bradshaw, Hershfeldt, \& Leaf, 2010).

Sejak akhir-akhir ini, isu tentang kesejahteraan guru mendapat perhatian dari pihak Kementerian Pendidikan Malaysia. Menteri Pendidikan Malaysia, Muhyiddin Bin Yasin (2013), menyatakan kerajaan sedang mencari satu formula bagi meningkatkan kesejahteraan guru dan memperbaiki persekitaran tempat kerja guru (Pelan Pembangunan Pendidikan Malaysia, 2013).

Kesejahteraan hidup guru akan memberikan impak yang besar terhadap bidang pendidikan di Malaysia. Sekiranya kesejahteraan hidup guru adalah rendah maka ini akan menyebabkan para guru cenderung untuk melahirkan ketidakpuasan, kebosanan, keletihan dan akan menjejaskan tahap kecekapan dalam meneruskan tugas. Situasi di sekolah yang tidak sejahtera serta tidak memotivasikan guru menyebabkan ramai dalam kalangan guru menunjukkan prestasi kerja yang tidak menggalakkan (Abdullah Shukor, Abd Rahim, \& Mohamad Yazi, 2006; Lopez, 2010).

Ramai majikan telah sedar bahawa pendekatan ke arah kesejahteraan yang positif di tempat kerja akan menghasilkan output atau hasil, sebagai contoh ianya akan meningkatkan efikasi kerja dan produktiviti (Briner \& Dewberry, 2007; Bajorek, 2013). Dalam usaha meningkatkan kualiti dan efikasi kerja guru secara kolektif faktor 
kesejahteraan hidup guru perlulah diambil berat agar kesejahteraan guru di tempat kerja dapat ditingkatkan dan seterusnya tahap efikasi kerja guru secara kolektif juga dapat ditingkatkan. Terdapat beberapa pandangan tentang persoalan kesejahteraan guru. Nelson (2003) menyatakan bahawa adalah sangat penting untuk mengenal pasti bagaimana perasaan guru tentang peranan mereka kerana ianya mempunyai kesan kepada efikasi kerja guru.

Di samping itu, keserakanan guru juga berkait rapat dengan kesejahteraan guru. Walaupun konsep keserakanan guru telah mendapat perhatian dalam kalangan pentadbir bidang pendidikan dan penyelidik sejak beberapa tahun yang lalu, tetapi keperluan penyelidikan dalam topik ini masih diperlukan di negara membangun seperti Malaysia. Tinjauan persoalan kajian menunjukkan kebanyakan kajian berkaitan dengan keserakanan guru telah dijalankan di Amerika Syarikat (Gable, Mostert, \& Tonelson, 2004; Goddard, 2007; Numeroff, 2005; Hallinger \& Heck, 2010). Dapatan kajian tersebut tidak mewakili semua pihak disebabkan perbezaan budaya, konteks dan matlamat pendidikan. Sehingga kini, kebanyakan dapatan kajian terhadap hubungan keserakanan pekerja dan efikasi tidak secara spesifik di sekolah atau guru. Keserakanan guru memberikan kesan yang positif terhadap kecemerlangan organisasi, tetapi terdapat perbezaan yang signifikan antara keserakanan guru bagi dua jenis sekolah iaitu sekolah yang mempunyai pencapaian tinggi dan sekolah yang mempunyai pencapaian yang rendah (Madiha Shah, 2011). Guru yang bekerja di persekitaran sekolah yang mempunyai budaya keserakanan yang tidak baik mempunyai tahap kesejahteraan dan kepuasan yang rendah. Keserakanan guru-guru di sekolah adalah penting untuk kecemerlangan sekolah dan kesejahteraan guru-guru.

Hubungan guru dengan rakan sekerja merupakan faktor terbesar yang menyebabkan guru kekal komited. Hubungan keserakanan guru mempunyai hubungan yang kuat dengan pencapaian pelajar. Keserakanan guru-guru merupakan satu elemen penting terhadap kecemerlangan dan efikasi guru. Didapati bahawa hubungan keserakanan yang kuat dalam kalangan guru akan meningkatkan kualiti pengajaran guru dan akan meningkatkan efikasi guru secara kolektif (Goddard \& Tschannen-Moran, 2007; Skaalvik, 2008; Fuchs \& Edwards, 2012). 
Dapatan kajian tersebut disokong oleh dapatan kajian daripada Goddard (2007) yang menyatakan bahawa hubungan keserakanan yang kuat dalam kalangan guru adalah berkait rapat dengan efikasi guru. Guru yang mempunyai tahap keserakanan yang tinggi di sekolah akan lebih komited di dalam organisasi. Namun demikian, dapatan kajian yang telah dijalankan oleh Little, Gearhart, Curry dan Kafta (2006) pula mendapati sebaliknya, keserakanan guru tidak boleh dihubungkan dengan pencapaian pelajar di sekolah. Pengukuhan hubungan di antara guru-guru tidak semestinya akan diterjemahkan kepada efikasi pengajaran guru. Bagaimanapun terdapat ramai pengkaji yang telah mengkaji hubungan antara keserakanan dan efikasi guru dalam bidang pendidikan dan menyatakan bahawa keserakanan mempunyai hubungan yang positif dengan komitmen dan efikasi guru (Woods \& Weasmer, 2002; Numeroff, 2005; Knapp, 2003; Jarzabkowski, 2003; Wang, Odell, Schwille, 2008; Williams, Prestage, \& Bedward, 2001; Tschannen-Moran, 2001; Abdullah, 2009).

Dalam kajian ini, pengkaji akan memperkenalkan kesejahteraan guru di tempat kerja sebagai pemboleh ubah pengantara (mediator) bagi menerangkan hubungan kesejahteraan hidup guru dan keserakanan guru dengan efikasi guru secara kolektif. Persoalan kajian mendapati terdapat ramai pengkaji yang bersetuju bahawa persekitaran di tempat kerja mempunyai kesan yang sangat penting terhadap efikasi kerja dan pembentukan sikap individu (Xiaofu, \& Qiwen, 2007; Ghitulescu, 2013).

Namun begitu masih terdapat beberapa orang pengkaji yang berpandangan sebaliknya, mereka berpendapat bahawa hanya konsep kesejahteraan tertentu sahaja yang sesuai diaplikasikan dalam bidang pendidikan (Little, 2006; Supovitz, 2003). Memandangkan wujudnya pelbagai pandangan ini, maka kajian perlu dijalankan bagi menentukan pemboleh ubah dan faktor yang mendorong efikasi kerja guru secara kolektif.

Masih kurang kajian yang dilakukan atas aspek kesejahteraan hidup guru, keserakanan guru dan kesejahteraan guru di tempat kerja dengan efikasi guru secara kolektif. Berdasarkan tinjauan persoalan kajian, masih belum terdapat kajian yang menerangkan hubungan secara langsung dan tidak langsung antara pemboleh ubah 
kesejahteraan hidup guru, keserakanan guru, kesejahteraan guru di tempat kerja dan efikasi guru secara kolektif di dalam satu kajian. Kajian ini adalah bagi mengisi jurang tersebut dengan menganalisis hubungan di antara kesejahteraan hidup guru, keserakanan guru, kesejahteraan guru di tempat kerja dan efikasi guru secara kolektif. Model hubungan di antara semua pemboleh ubah ini berdasarkan Teori Kognitif Sosial yang diperkenalkan oleh Bandura (1986, 1997). Teori ini menyatakan bahawa tingkah laku manusia merupakan satu tindak balas terhadap faktor personal, tingkah laku dan persekitaran. Dalam kajian ini, efikasi kolektif guru mewakili penentu tingkah laku; keserakanan guru dan kesejahteraan guru di tempat kerja pula mewakili penentu persekitaran dan kesejahteraan hidup guru mewakili penentu personal.

Walau bagaimanapun, kajian tentang hubungan antara kesejahteraan hidup, keserakanan guru, kesejahteraan di tempat kerja dan efikasi guru secara kolektif di Malaysia masih terhad. Mekanisme untuk memahami pengaruh tersebut tidak dijalankan secara empirikal dan komprehensif terutamanya dalam konteks di Malaysia. Pengkajipengkaji di dalam bidang efikasi kolektif guru seperti Caprara, Barbaranelli, Steca dan Malone, (2006), Pas, Bradshaw, Schaufeli dan Salanova, (2007), Skaalvik dan Skaalvik, (2007) mula mencari kaedah terbaik bagi meningkatkan efikasi kolektif guru. Dalam aspek ini, pengkaji tidak hanya melihat kepada individu guru, tetapi juga faktor sosial dan budaya dalam aspek pendidikan (Hodkinson \& Hodkinson, 2005; Jewezyn, 2010; Klassen, 2010).

\section{OBJEKTIF KAJIAN}

Objektif kajian ini adalah untuk menerangkan tahap kesejahteraan hidup guru, keserakanan guru, kesejahteraan guru di tempat kerja dan efikasi guru secara kolektif. Seterusnya kajian ini juga bertujuan untuk menjelaskan hubungan di antara kesejahteraan guru di tempat kerja, kesejahteraan hidup guru dan keserakanan guru dengan efikasi guru secara kolektif serta mengenal pasti sama ada kesejahteraan guru di tempat kerja berperanan sebagai pemboleh ubah pengantara yang signifikan bagi menerangkan hubungan di antara kesejahteraan hidup guru, keserakanan guru dan efikasi guru secara kolektif dengan menggunakan analisis model persamaan berstruktur. 
Oleh yang demikian, kajian ini dapat membantu memberi pemahaman yang lebih jelas tentang faktor penyumbang kepada efikasi guru secara kolektif, secara langsung dan tidak langsung, dan melihat sejauh mana kesejahteraan guru di tempat kerja mempengaruhi hubungan di antara kesejahteraan hidup guru dan keserakanan guru dengan efikasi kerja guru secara kolektif.

\section{METODOLOGI}

\section{Sampel}

Responden dalam kajian ini adalah dari populasi guru Maktab Rendah Sains Mara yang dipilih dengan menggunakan tiga peringkat iaitu kaedah persampelan kluster, persampelan rawak mudah dan persampelan rawak mudah sistematik. Pada peringkat pertama, teknik persampelan kluster atau kawasan melibatkan pembahagian populasi kepada kawasan atau kluster yang tidak bertindih. Prosedur untuk memilih kluster Zon Timur secara rawak adalah memenuhi kriteria persampelan kluster, sejenis teknik persampelan kebarangkalian (Ary, Jacobs \& Razavieh, 2002). Peringkat persampelan kedua adalah secara rawak mudah bagi memilih beberapa buah Maktab Rendah Sains Mara daripada kluster Zon Timur. Pada peringkat ketiga teknik persampelan rawak mudah sistematik digunakan bagi memilih 80 orang guru bagi setiap Maktab Rendah Sains Mara yang dipilih.

Responden kajian ini melibatkan $63.4 \%$ guru perempuan $(n=530)$ dan $36.6 \%$ guru lelaki $(n=306)$. Taburan responden mengikut umur di bawah 30 tahun ialah seramai 33.5\% $(n=280)$ di antara 31 hingga 40 tahun iaitu $37.7 \%(n=315)$. Guru yang berumur di antara 41 hingga 50 tahun seramai $22.7 \%(\mathrm{n}=190)$ manakala guru yang berumur 51 tahun ke atas hanya 6.1\% $(\mathrm{n}=51)$. Jumlah keseluruhan sampel kajian adalah 836 .

\section{Prosedur}

Kajian ini telah dijalankan mengikut prosedur yang dicadangkan oleh Ary, Jacobs dan Razavieh (2005) bagi menentukan tahap kesahan dalaman dan luaran kajian dijalankan dengan sebaiknya. Dua peringkat kajian rintis telah dijalankan bagi menentukan 
kesahihan kajian dan kebolehpercayaan terhadap item soal selidik. Data kajian ini telah melalui proses pengimbasan data, analisis kebolehpercayaan dan kesahan seperti yang dicadangkan oleh Tabachnick dan Fidell (2007) dan Hair, Black, Babin, Anderson dan Tatham (2006). Penilaian terhadap model pengukuran gabungan (Pooled CFA), menunjukkan kesepadanan yang baik antara model dan data, iaitu nilai $\chi^{2} / \mathrm{df}=1.28$, RMSEA $=.028$ (kurang daripada .08) (Browne \& Cudeck, 1993), (TLI = .957 dan CFI $=.960$ (lebih besar daripada .90) (Bentler, 1990).

Analisis deskriptif yang melibatkan min dan sisihan piawai digunakan bagi mengukur tahap bagi kesemua pemboleh ubah kajian. Analisis korelasi yang memperbaiki ralat pengukuran (dissattenuated correlation) dihitung menggunakan AMOS versi 21.0 bagi melihat hubungan antara kesemua pemboleh ubah kajian. Manakala Analisis Model Persamaan Berstruktur dijalankan bagi menguji peranan kesejahteraan guru di tempat kerja sebagai pemboleh ubah pengantara hubungan kesejahteraan hidup guru, keserakanan guru dan efikasi guru secara kolektif. Kajian ini menggunakan indeks ukuran padanan yang selalu digunakan sebagai penanda aras dalam menentukan kebagusuaian padanan sesuatu model, antaranya root mean-square error of approximation (RMSEA), comparative fit

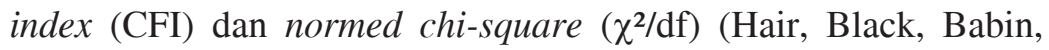
Anderson \& Tatham, 2006).

\section{Instrumen}

Dalam kajian ini, soal selidik telah digunakan sebagai alat ukur untuk mengutip data. Instrumen kajian ini menggunakan sepuluh skala. Item-item dalam kajian ini telah disemak dari segi kesahan kandungan dan kebolehpercayaan. Analisis faktor digunakan untuk menyemak kesahan instrumen. Pengujian nilai Cronbach Alpha telah dijalankan bagi menentukan ketekalan dalaman dan kebolehpercayaan instrumen kajian. Kebolehpercayaan soal selidik adalah tinggi; hasil analisis Cronbach Alpha bagi pemboleh ubah kesejahteraan hidup adalah 0.93, keserakanan guru adalah 0.87, kesejahteraan di tempat kerja adalah 0.92 dan efikasi guru secara kolektif adalah 0.95 .

Instrumen Kesejahteraan Hidup Guru: Instrumen Indeks Kesejahteraan Hidup $(2002,2005)$ yang terdiri daripada 9 item 
digunakan bagi menilai kepuasan manusia terhadap kehidupan peribadi dan kehidupan bermasyarakat (cth., 'Sejauh manakah anda berpuas hati dengan taraf kehidupan anda?'). Nilai alpha koefisien bagi ketekalan dalaman adalah konsisten dengan kajian-kajian lepas (kajian rintis peringkat pertama $\alpha=.90$; kajian rintis peringkat kedua $\alpha=.93$ ). Skala yang digunakan untuk mengukur pemboleh ubah adalah berdasarkan kepada Skala Likert yang bernilai 0 (sangat tidak berpuas hati) hingga 10 (sangat berpuas hati).

Instrumen Keserakanan Guru: Instrumen oleh Madiha Shah (2011) digunakan bagi mengukur keserakanan guru yang terdiri daripada 38 item yang mewakili tujuh sub-skala seperti sokongan dan kepercayaan, pemantauan pengajaran, perancangan dan penilaian bersama, perkongsian idea dan kepakaran, belajar di antara satu sama lain, pembangunan kurikulum bersama dan perkongsian sumber (contoh., 'Saya dan rakan-rakan bekerjasama menganalisis pengajaran'). Nilai alpha koefisien bagi instrumen ini adalah di antara .85 hingga .87 . Skala yang digunakan untuk mengukur pemboleh ubah adalah berdasarkan kepada Skala Likert yang bernilai 0 (sangat tidak berpuas hati) hingga 10 (sangat berpuas hati).

Instrumen Kesejahteraan di Tempat Kerja: Indeks kesejahteraan di tempat kerja oleh Kathryn Page (2005) yang terdiri daripada 12 item digunakan bagi mengukur kepuasan hati terhadap tempat kerja berdasarkan faktor dalaman dan luaran (contoh., 'Kerja anda secara keseluruhan di sekolah ini'). Guru memberi respon berdasarkan kepada Skala Likert yang bernilai 0 (sangat tidak berpuas hati) hingga 10 (sangat berpuas hati). Nilai alpha koefisien bagi instrumen ini adalah di antara .90 hingga .92 .

Instrumen Efikasi Guru Secara Kolektif: Skala kepercayaan guru secara kolektif oleh Tschannen-Moran dan Barr (2004) digunakan bagi mengukur kemampuan guru secara kolektif dalam strategi pengajaran dan dalam membentuk disiplin pelajar (contoh., 'Sejauh manakah sekolah dapat menyakinkan pelajar bahawa mereka mampu membuat kerja sekolah dengan baik'). Skala Likert yang digunakan adalah bernilai 0 (sangat tidak mampu) hingga 10 (sangat mampu). Nilai alpha koefisien bagi instrumen ini adalah di antara .93 hingga .95. 


\section{DAPATAN KAJIAN}

Bahagian ini akan membincangkan dapatan kajian berdasarkan tiga objektif kajian yang dibangunkan untuk kajian ini.

Objektif kajian 1: Tahap kesejahteraan hidup guru, keserakanan guru, kesejahteraan guru di tempat kerja dan efikasi guru secara kolektif.

Pengukuran tahap bagi kesejahteraan hidup guru dilakukan dengan menghitung purata skor. Didapati purata pemboleh ubah kesejahteraan hidup guru $(\mathrm{M}=7.98, \mathrm{SP}=1.18)$. Pengukuran purata skor bagi keserakanan guru $(\mathrm{M}=8.07, \mathrm{SP}=1.11)$ adalah melebihi sedikit purata skor kesejahteraan guru di tempat kerja $(\mathrm{M}=7.96, \mathrm{SP}=1.15)$. Analisis menunjukkan bahawa purata skor untuk kesejahteraan hidup guru, kesejahteraan di tempat kerja dan keserakanan guru cenderung kepada berpuas hati. Purata skor terendah adalah efikasi kolektif guru $(\mathrm{M}=7.55, \mathrm{SP}=1.58)$. Analisis menunjukkan bahawa purata skor untuk efikasi kolektif guru adalah cenderung kepada mampu.

Jadual 1

Purata dan Sisihan Piawai bagi Semua Pemboleh Ubah

\begin{tabular}{lcc}
\hline & Purata & Sisihan Piawai \\
\hline Kesejahteraan Hidup Guru & 7.98 & 1.18 \\
Keserakanan Guru & 8.07 & 1.11 \\
Kesejahteraan Guru di tempat Kerja & 7.96 & 1.15 \\
Efikasi Guru Secara Kolektif & 7.55 & 1.28 \\
\hline
\end{tabular}

Objektif kajian 2: Hubungan antara kesejahteraan guru di tempat kerja, kesejahteraan hidup guru dan keserakanan guru dengan efikasi guru secara kolektif.

Analisis korelasi yang memperbaiki ralat pengukuran(dissattenuated correlation) dihitung menggunakan AMOS versi 21.0 bagi melihat hubungan antara kesemua pemboleh ubah kajian. Jadual 2 menunjukkan hubungan antara pemboleh ubah kesejahteraan hidup guru, keserakanan guru, kesejahteraan guru di tempat kerja dan efikasi guru secara kolektif. 
Hubungan yang paling kuat adalah antara kesejahteraan di tempat kerja dengan efikasi kolektif guru, $\mathrm{r}=.62, \mathrm{t}=17.6, \mathrm{p}<.001$. Sebagaimana yang dijangka terdapat hubungan secara positif antara kesejahteraan di tempat kerja dengan efikasi kolektif guru. Hal ini bermaksud semakin meningkat kesejahteraan di tempat kerja maka semakin tinggi tahap efikasi kolektif guru. Hubungan yang paling lemah adalah antara kesejahteraan hidup guru dengan kesejahteraan di tempat kerja, $\mathrm{r}=.32, \mathrm{t}=9.4, \mathrm{p}<.001$.

Analisis dapatan kajian ini juga mendapati keserakanan guru mempunyai hubungan positif yang signifikan dengan efikasi kolektif guru, $\mathrm{r}=.78, \mathrm{t}=26.8, \mathrm{p}<.001$. Hubungan antara kesejahteraan hidup dengan keserakanan guru adalah positif dan signifikan, $\mathrm{r}=$ $.66, \mathrm{t}=30.4, \mathrm{p}<.001$. Hubungan antara keserakanan guru dengan kesejahteraan di tempat kerja juga adalah positif yang signifikan, $\mathrm{r}=.55, \mathrm{t}=20.8, \mathrm{p}<.001$. Hubungan antara kesejahteraan hidup dengan efikasi kolektif guru juga adalah positif yang signifikan, $r$ $=.59, \mathrm{t}=16.1, \mathrm{p}<.001$. Ini bermaksud apabila tahap kesejahteraan hidup guru dan keserakanan guru meningkat maka ianyanya akan meningkatkan tahap kesejahteraan di tempat kerja dan tahap efikasi kolektif guru juga akan meningkat.

Jadual 2

Hubungan Korelasi yang Memperbaiki Ralat Pengukuran (Disattenuated Correlation) berdasarkan Kesejahteraan Hidup Guru, Keserakanan Guru, Kesejahteraan Guru di Tempat Kerja dan Efikasi Guru secara Kolektif

\begin{tabular}{lcccc}
\hline & 1 & 2 & 3 & 4 \\
\hline Kesejahteraan Hidup Guru & 1.00 & & & \\
Keserakanan Guru & $.66^{* * *}$ & 1.00 & & \\
Kesejahteraan Guru di tempat Kerja & $.32^{* * *}$ & $.55^{* * *}$ & 1.00 & \\
Efikasi Guru secara Kolektif & $.59 * * *$ & $.78^{* * *}$ & $.62^{* * *}$ & 1.00 \\
Purata & 7.98 & 8.07 & 7.96 & 7.55 \\
Sisihan Piawai & 1.18 & 1.11 & 1.16 & 1.28 \\
\hline$* * * \mathrm{p}<.001$ & & & &
\end{tabular}

Objektif kajian 3: Mengenal pasti sama ada kesejahteraan guru di tempat kerja berperanan sebagai pemboleh ubah pengantara yang signifikan bagi menerangkan hubungan di antara kesejahteraan hidup guru, keserakanan guru dan efikasi guru secara kolektif dengan menggunakan model persamaan berstruktur. 
Penilaian ke atas model struktural mendapati secara keseluruhan terdapat kesepadanan yang baik antara model dan data. Nilai $2 / \mathrm{df}$ $=2.68$ (kurang daripada tiga), RMSEA=.06 (kurang daripada .08) dan SRMR=.05 (kurang daripada .08) menunjukkan model fit yang baik. Nilai indeks TLI $=.97$ dan nilai indeks CFI $=.97$, kedua-dua nilai indeks ini menunjukkan nilai yang lebih besar daripada .90 . Dapatan pengujian model hipotesis dan penganggaran kesemua parameter ditunjukkan dalam model berstruktur pada rajah 1 .
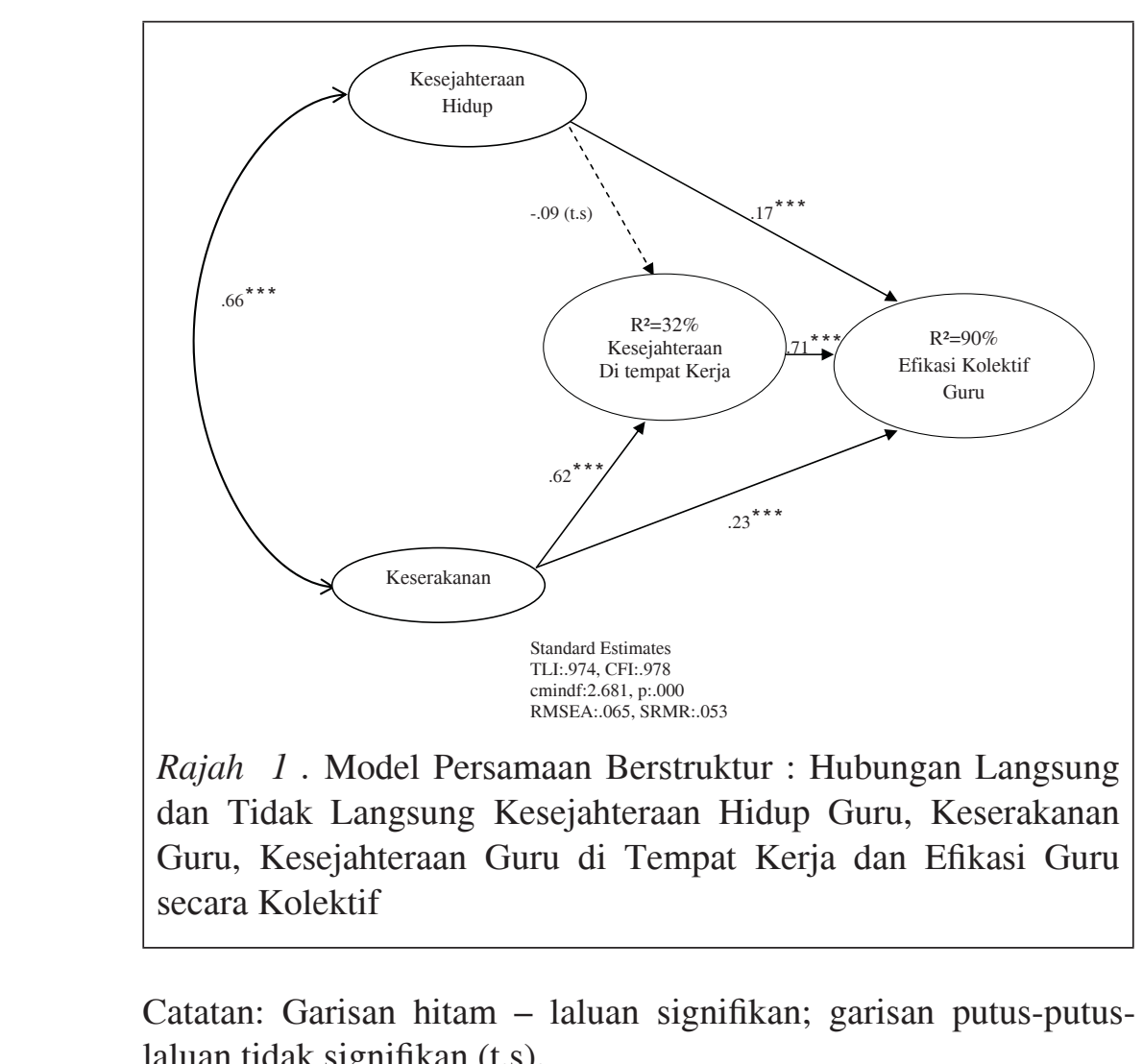

Catatan: Garisan hitam - laluan signifikan; garisan putus-putuslaluan tidak signifikan (t.s).

$* * * \mathrm{p}<.001$

Dapatan analisis ini membolehkan penilaian tentang setiap laluan koefisien dijalankan. Berdasarkan model struktural terdapat enam koefisien laluan yang dianggar dalam model tersebut. Enam koefisien laluan berkenaan hubungan antara kesejahteraan hidup, keserakanan dan kesejahteraan di tempat kerja dengan efikasi guru secara kolektif. Daripada enam laluan tersebut hanya satu laluan 
menunjukkan pekali koefisien yang tidak signifikan. Ringkasan pekali koefisien, nilai kritikal dan aras signifikan ditunjukkan dalam Jadual 3.

Jadual 3

Pekali Koefisien bagi Laluan dalam Model Persamaan Berstruktur

\begin{tabular}{lcrl}
\hline Laluan & \multicolumn{1}{c}{$\beta$} & \multicolumn{1}{c}{$\mathrm{t}$} & $\mathrm{p}$ \\
\hline Kesejahteraan hidup - kesejahteraan di tempat kerja & -.09 & -1.94 & .053 \\
Keserakanan Kesejahteraan di tempat kerja & .62 & 12.42 & $.000^{* * * *}$ \\
Kesejahteraan di tempat kerja Efikasi kolektif guru & .71 & 12.36 & $.000^{* * *}$ \\
Kesejahteraan hidup Efikasi kolektif guru & .17 & 3.45 & $.000^{* * *}$ \\
Keserakanan guru Efikasi Kolektif Guru & .23 & 4.04 & $.000^{* * *}$ \\
Kesejahteraan hidup keserakanan & .66 & 30.12 & $.000^{* * *}$ \\
\hline
\end{tabular}

$* * * \mathrm{p}<.001$

Kesemua laluan hubungan antara setiap pemboleh ubah adalah signifikan kecuali laluan kesejahteraan hidup ke kesejahteraan di tempat kerja $(\beta=-.09, \mathrm{t}=-1937, \mathrm{p}>.05)$. Faktor keserakanan guru mempunyai pengaruh yang tinggi terhadap kesejahteraan di tempat kerja $(\beta=.62, \mathrm{t}=12.4, \mathrm{p}<.001)$. Laluan positif yang signifikan memberi erti bahawa keserakanan guru mempengaruhi kesejahteraan di tempat kerja. Faktor kesejahteraan guru di tempat kerja juga mempunyai pengaruh yang signifikan terhadap efikasi kolektif guru $(\beta=.71, \mathrm{t}=12.4, \mathrm{p}<.001)$. Kajian ini membuktikan bahawa terdapat hubungan langsung di antara kesejahteraan guru di tempat kerja dengan efikasi kerja guru secara kolektif dan di antara keserakanan guru dengan efikasi kerja guru secara kolektif.

Bagi hubungan antara kesejahteraan hidup guru dan keserakanan guru dengan efikasi kerja guru secara kolektif kedua laluan adalah signifikan $(\beta=.17, \mathrm{t}=3.4, \mathrm{p}<.001)$ dan $(\beta=.23, \mathrm{t}=4.0, \mathrm{p}<.001)$.

\section{a) Pengujian Kesejahteraan di tempat Kerja sebagai Pengantara terhadap Hubungan antara Keserakanan dengan Efikasi Guru Secara Kolektif}

Kajian ini menggunakan analisis grafik Analysis Of Moment Structures (AMOS) untuk mengenal pasti peranan kesejahteraan di tempat kerja sebagai pengantara terhadap hubungan antara 
keserakanan guru dengan efikasi guru secara kolektif seperti yang disyorkan oleh Baron dan Kenny (1986) dan Zainuddin Awang (2012).

Jadual 4

Hubungan langsung Keserakanan Guru dengan Efikasi Guru Secara Kolektif

\begin{tabular}{lrc}
\hline Laluan & $\beta$ & $\mathrm{p}$ \\
\hline Keserakanan guru Efikasi guru secara kolektif & .56 & $.001 * * *$ \\
\hline$* * * \mathrm{p}<.001$ & &
\end{tabular}

Langkah pertama adalah menetapkan pemboleh ubah bebas dan pemboleh ubah bersandar. Dalam langkah ini, pemboleh ubah bebas dikenal pasti sebagai Keserakanan guru, pemboleh ubah bersandar ialah Efikasi Guru secara Kolektif manakala pemboleh ubah pengantara ialah Kesejahteraan di Tempat Kerja. Analisis pengujian pengantara bermula dengan menunjukkan kesan langsung keserakanan guru terhadap efikasi guru secara kolektif adalah signifikan $(\beta=.56, \mathrm{t}=10.2, \mathrm{p}<.001)$ seperti Jadual 4. Kesan langsung diukur dengan melihat kepada nilai pekali beta, dalam kes ini ianya adalah signifikan.

Jadual 5

Kesejahteraan di Tempat Kerja sebagai pengantara terhadap Hubungan antara Keserakanan Guru dengan Efikasi Guru Secara Kolektif

\begin{tabular}{lcc}
\hline Laluan & $\beta$ & $\mathrm{p}$ \\
\hline Keserakanan guru Kesejahteraan di tempat kerja & .49 & $.001 * * *$ \\
Keserakanan guru Efikasi guru secara kolektif & .27 & $.001 * * *$ \\
Kesejahteraan di tempat kerja Efikasi guru secara kolektif & .77 & $.001 * * *$ \\
\hline
\end{tabular}
$* * * \mathrm{p}<.001$

Apabila pemboleh ubah pengantara dimasukkan ke dalam model, nilai pekali beta bagi pemboleh ubah keserakanan guru didapati menurun, iaitu kesan langsung keserakanan guru terhadap efikasi 
guru secara kolektif menurun apabila pemboleh ubah pengantara dimasukkan ke dalam model. Model yang baru setelah pemboleh ubah pengantara dimasukkan ditunjukkan oleh rajah 2 .

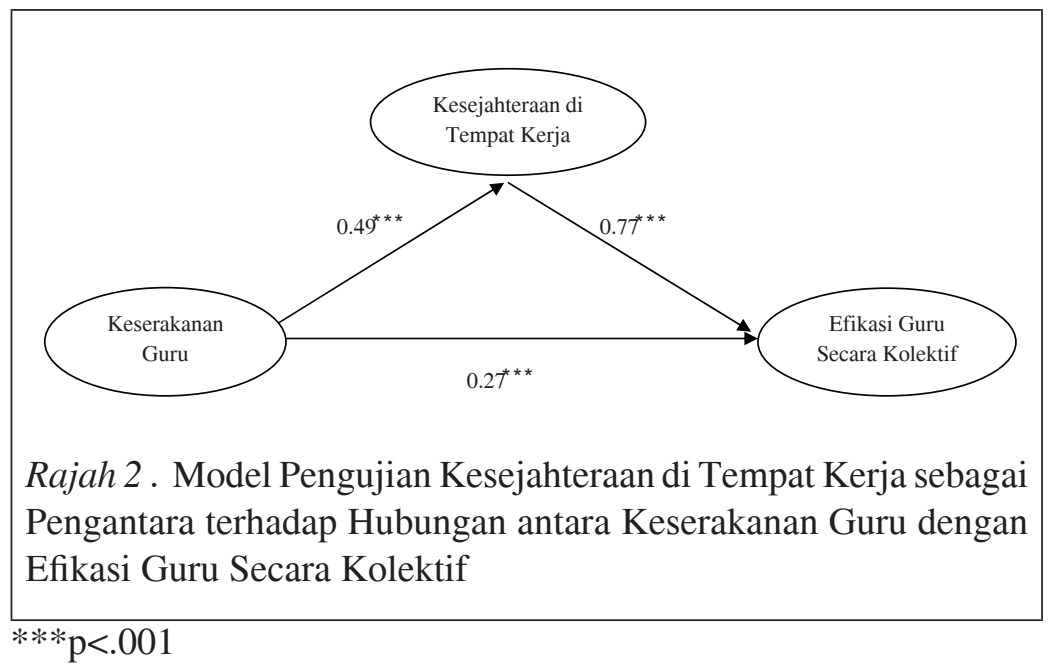

Rajah 2 menunjukkan pemboleh ubah kesejahteraan di tempat kerja berperanan sebagai pengantara antara hubungan keserakanan guru dengan efikasi guru secara kolektif. Pemerhatian terhadap nilai pekali beta yang menghubungkan keserakanan guru dengan efikasi guru secara kolektif adalah menurun daripada .56 (Jadual 4) kepada .27 (Jadual 5). Hal ini menunjukkan kesan langsung telah menurun selepas pemboleh ubah dimasukkan ke dalam model.

Dapatan kajian ini menunjukkan pemboleh ubah kesejahteraan di tempat kerja berperanan sebagai pemboleh ubah pengantara hubungan antara keserakanan guru dan efikasi guru secara kolektif. Keputusan ini membolehkan pemboleh ubah kesejahteraan di tempat kerja di kenal pasti sebagai pengantara separa, ini disebabkan oleh kesan langsung keserakanan guru terhadap efikasi guru secara kolektif masih signifikan selepas kesejahteraan di tempat kerja dimasukkan ke dalam model walaupun nilai pekali beta menurun daripada .56 kepada .27. Dalam kajian ini, keserakanan guru mempunyai hubungan langsung yang signifikan terhadap efikasi guru secara kolektif dan juga mempunyai hubungan tidak langsung yang signifikan terhadap efikasi guru secara kolektif melalui pemboleh ubah pengantara iaitu kesejahteraan di tempat kerja. 
Analisis ujian Bootstrapping (Hair, 2006; Zainudin, 2012) dijalankan untuk mengesahkan kesejahteraan di tempat kerja sebagai pengantara yang signifikan di antara keserakanan guru dengan efikasi guru secara kolektif. Jadual 6 menunjukkan bahawa kesejahteraan di tempat kerja merupakan pengantara yang signifikan bagi keserakanan guru terhadap efikasi guru secara kolektif.

Jadual 6

Ujian Bootstrapping Kesan Langsung dan Kesan Tidak Langsung Kesejahteraan di Tempat Kerja sebagai Pengantara Keserakanan Guru terhadap Efikasi Guru Secara Kolektif

\begin{tabular}{lcc}
\hline & Kesan Tidak Langsung & Kesan Langsung \\
\hline Nilai P & .001 & .002 \\
Keputusan & Signifikan & Signifikan \\
\hline Kesimpulan & Jenis Pengantara Separa \\
\hline
\end{tabular}

Secara langsung kesan keserakanan guru terhadap efikasi guru secara kolektif adalah signifikan $(\beta=.27, \mathrm{p}<0.05)$. Secara tidak langsung kesan keserakanan guru terhadap efikasi guru secara kolektif melalui pengantara kesejahteraan di tempat kerja adalah juga signifikan $(\beta=.23, \mathrm{p}<0.05)$. Keputusan analisis menunjukkan kesan langsung dan tidak langsung adalah signifikan selepas pemboleh ubah pengantara kesejahteraan di tempat kerja dimasukkan ke dalam model. Dapatan analisis menggunakan kaedah Bootstrapping adalah selari dengan dapatan pengujian menggunakan analisis grafik Analysis Of Moment Structures (AMOS) serta menyokong keputusan analisis yang membuktikan bahawa kesejahteraan di tempat kerja berperanan sebagai pengantara separa.

\section{PERBINCANGAN}

Dapatan kajian ini menilai peranan kesejahteraan hidup, keserakanan, kesejahteraan di tempat kerja dalam menerangkan efikasi guru secara kolektif. Kajian ini menerangkan hubungan secara langsung dan tidak langsung di antara pemboleh ubah kesejahteraan hidup guru, keserakanan guru, kesejahteraan guru di tempat kerja dan efikasi guru secara kolektif di dalam satu kajian. Kajian ini 
juga memperkenalkan model yang menunjukkan kepentingan kesejahteraan hidup, keserakanan dan kesejahteraan di tempat kerja sebagai penyumbang yang signifikan kepada efikasi guru secara kolektif. Ia juga mengenal pasti kepentingan keserakanan guru dalam membangunkan efikasi guru secara kolektif.

\section{a) Peranan Kesejahteraan Hidup, Keserakanan dan Kesejahteraan di Tempat Kerja dalam meningkatkan Efikasi Guru Secara Kolektif}

Kesejahteraan hidup mempunyai kesan langsung yang signifikan terhadap efikasi guru secara kolektif. Secara langsung apabila guru memperoleh kesejahteraan hidup maka ia memberi pengaruh yang baik terhadap efikasi guru secara kolektif. Dapatan ini selaras dengan dapatan kajian terdahulu yang dikendalikan oleh Klassen, Usher dan Bong (2009) yang mendapati bahawa kesejahteraan guru adalah berkait rapat dengan efikasi kerja. Kesejahteraan hidup yang positif akan menghasilkan output atau hasil, sebagai contoh ianya akan meningkatkan efikasi kerja dan produktiviti. Malah dapatan kajian ini tidak menghairankan kerana menurut Yong dan Yue (2007) yang mendapati konflik di antara efikasi kerja dan kesejahteraan hidup guru memberi kesan yang negatif terhadap proses pengajaran dan pembelajaran. Kesejahteraan hidup guru didapati memberi kesan langsung kepada budaya pembelajaran di sekolah dan efikasi guru.

Begitu juga dengan aspek keserakanan guru yang mempunyai kesan langsung yang signifikan terhadap efikasi guru secara kolektif. Ini bermakna, secara langsung apabila tahap hubungan keserakanan guru adalah memuaskan maka ia akan memberi impak yang baik terhadap efikasi guru secara kolektif. Dapatan kajian ini menyokong Bolam (2005), Goddard (2007) dan Madiha (2011) apabila pengkajipengkaji ini mendapati bahawa keserakanan guru merupakan satu elemen penting terhadap kecemerlangan dan efikasi sekolah. Didapati bahawa hubungan keserakanan yang kuat di kalangan guru akan meningkatkan kualiti pengajaran guru dan akan meningkatkan efikasi kerja guru.

Dapatan kajian ini menunjukkan bahawa keserakanan guru mempunyai pengaruh yang signifikan terhadap kesejahteraan di tempat kerja. Dapatan ini menggambarkan bahawa terdapat 
pengaruh yang positif antara keserakanan guru dan kesejahteraan di tempat kerja. Keputusan ini juga menjelaskan bahawa apabila hubungan keserakanan adalah baik, maka ia akan meningkatkan kesejahteraan di tempat kerja. Hasil kajian ini adalah konsisten dengan kajian yang dilakukan oleh Tatlah, Ali dan Saeed (2011) yang menyatakan bahawa hubungan keserakanan mempunyai kesan yang positif terhadap kesejahteraan di tempat kerja. Dapatan kajian ini menyokong Retallick dan Butt (2004) menyatakan bahawa hubungan keserakanan guru di tempat kerja mempunyai hubungan dengan kesejahteraan guru di tempat kerja. Guru-guru yang mempunyai hubungan keserakanan yang positif di tempat kerja akan merasa lebih selesa untuk mendapatkan bantuan profesional daripada rakan-rakan mereka. Dapatan kajian ini juga selari dengan dapatan kajian oleh Day (2000) yang menyatakan bahawa hubungan keserakanan mempunyai kesan yang positif terhadap kesejahteraan di tempat kerja. Hubungan keserakanan yang baik di antara guru dan pihak pentadbir di sekolah merupakan asas kepada kesejahteraan guru di tempat kerja.

Kajian ini mendapati efikasi guru secara kolektif dipengaruhi secara positif oleh kesejahteraan di tempat kerja secara langsung. Ini bermakna untuk meningkatkan efikasi guru secara kolektif, guru perlu meningkatkan tahap kesejahteraan di tempat kerja. Tahap kepuasan guru terhadap kesejahteraan di tempat kerja akan memberi kesan langsung dan berkait rapat dengan tahap kemampuan dan efikasi guru secara kolektif. Dapatan ini selari dengan kajian yang telah dijalankan oleh Briner dan Dewberry (2007) mendapati bahawa terdapat hubungan yang signifikan di antara kesejahteraan guru di sekolah dengan efikasi kerja guru secara kolektif.

\section{b) Pentingnya Keserakanan untuk meningkatkan Kesejahteraan di tempat Kerja}

Keserakanan guru juga mempunyai hubungan yang tidak langsung yang signifikan terhadap efikasi guru secara kolektif melalui pemboleh ubah pengantara iaitu kesejahteraan di tempat kerja. Keserakanan guru mempengaruhi kesejahteraan di tempat kerja yang akhirnya mempengaruhi efikasi guru secara kolektif. Justeru keserakanan guru yang tinggi mampu membina kesejahteraan guru di tempat kerja dan mendorong peningkatan efikasi guru secara kolektif. 
Di dalam kajian ini pengkaji merujuk kepada konsep keserakanan guru yang diketengahkan oleh Jarzabkowski (2002) yang menyatakan bahawa keserakanan guru adalah hubungan kerjasama di antara rakan-rakan sekerja dan penglibatan guru dengan rakanrakan sekerja pada semua tahap. Keserakanan guru melibatkan hubungan profesional dan hubungan interaksi sosial atau emosi di tempat kerja. Hubungan keserakanan yang kuat di antara guruguru di sekolah telah diberikan perhatian utama dan merupakan satu faktor penting terhadap peningkatan dan kecemerlangan sekolah (DuFour, 2004; Little, 2006).

Kajian ini memfokuskan kepada tujuh dimensi keserakanan guru yang diketengahkan oleh Madiha (2011) seperti sokongan dan kepercayaan, perancangan dan penilaian bersama, perkongsian idea dan kepakaran, belajar di antara satu sama lain, pembangunan kurikulum bersama, perkongsian sumber dan pemantauan pengajaran. Dimensi-dimensi keserakanan guru ini dipilih kerana ia paling tepat bagi menjelaskan definisi keserakanan guru yang diguna pakai di dalam kajian ini. Dimensi-dimensi keserakanan guru ini juga telah di uji di dalam kajian yang telah dijalankan di Pakistan (Madiha, 2011).

Kajian ini mencadangkan agar dimensi-dimensi keserakanan guru ini diberi perhatian agar tahap hubungan keserakanan di kalangan guru dapat ditingkatkan ke arah peningkatan kesejahteraan di tempat kerja dan efikasi kerja guru secara kolektif. Dapatan kajian ini juga menyokong dapatan kajian oleh Sarwar, Aslam dan Rasheed (2010) yang mendapati bahawa hubungan keserakanan yang kuat di antara guru-guru menjadi satu elemen penting di sekolah-sekolah berprestasi tinggi. Pengkaji-pengkaji yang lain pula mendapati bahawa keserakanan guru mempunyai kesan yang positif terhadap sikap dan pengajaran guru, meningkatkan kesejahteraan di tempat kerja, mengurangkan stres, meningkatkan efikasi, bermoral tinggi, meningkatkan pembangunan profesional, mengurangkan masalah guru berhenti kerja, membantu guru-guru baru serta meningkatkan tahap kepercayaan (Woods \& Weasmer, 2002; Numeroff, 2005; Knapp, 2003; Jarzabkowski, 2002; Wang, Odell, Schwille, 2008; Tschannen-Moran, 2001; Abdullah, 2009).

Kajian ini membuktikan bahawa kesejahteraan di tempat kerja hanya menjadi pengantara separa yang signifikan antara hubungan 
keserakanan dengan efikasi guru secara kolektif. Kesejahteraan di tempat kerja berperanan sebagai pengantara separa, ini disebabkan oleh kesan langsung keserakanan guru terhadap efikasi guru secara kolektif masih signifikan selepas kesejahteraan di tempat kerja dimasukkan ke dalam model. Kajian ini menyokong dapatan Baicker, Cutler dan Song (2010) yang menjelaskan kepentingan kesejahteraan di tempat kerja sebagai pengantara hubungan antara efikasi kerja dan kecemerlangan organisasi.

Justeru, kajian ini mencadangkan agar tahap hubungan keserakanan di kalangan guru diberi perhatian kerana faktor ini sangat penting demi kecemerlangan dan efikasi guru secara kolektif. Kajian ini juga mencadangkan agar persekitaran keserakanan di tempat kerja dibangunkan dan mencadangkan agar terdapat satu platform bagi guru-guru untuk bekerja secara kolektif ke arah membudayakan orientasi kerja berpasukan agar kesejahteraan di tempat kerja dan efikasi kerja secara kolektif dapat ditingkatkan.

\section{IMPLIKASI}

Kajian ini menganggarkan dan mengembangkan teori kognitif sosial dalam konteks kesejahteraan hidup guru, keserakanan guru, kesejahteraan guru di tempat kerja dan efikasi guru secara kolektif. Kajian ini berjaya menyokong teori kognitif sosial di mana pemboleh ubah - pemboleh ubah dalam kajian ini mempunyai pengaruh yang sangat besar kepada efikasi guru secara kolektif dalam konteks guru di Malaysia. Teori kognitif sosial dapat menjelaskan bagaimana keserakanan guru yang mewakili penentu persekitaran mempengaruhi secara positif kesejahteraan di tempat kerja. Penentu persekitaran iaitu keserakanan guru juga didapati mempunyai hubungan langsung dengan efikasi guru secara kolektif yang merupakan penentu tingkah laku.

Kajian ini membuktikan kesejahteraan di tempat kerja menjadi pengantara separa antara hubungan kesejahteraan hidup, keserakanan dan efikasi guru secara kolektif. Model struktural yang dicadangkan dalam kajian ini dapat menjelaskan isu kesejahteraan hidup dan keserakanan guru serta mencadangkan langkah-langkah yang perlu diambil oleh golongan pentadbir dalam bidang pendidikan untuk menggalakkan guru meningkatkan kesejahteraan di tempat kerja. 


\section{CADANGAN}

Kajian lanjutan boleh dijalankan di seluruh negara dengan melibatkan guru-guru sama ada dari sekolah menengah atau dari sekolah rendah. Soal selidik kajian ini juga boleh digunakan ke atas populasi yang berbeza dari segi tempat dan juga unit kajian.

Dalam kajian ini, penyelidik hanya menggunakan instrumen soal selidik sahaja. Kajian lanjutan dicadangkan supaya menggunakan kaedah kualitatif lain seperti kaedah pemerhatian atau temu bual untuk mendapatkan maklumat yang lebih lengkap dan menyokong dapatan kajian. Penggunaan pelbagai kaedah ini boleh membantu penyelidik untuk mengenal pasti faktor lain yang turut mempengaruhi efikasi guru secara kolektif.

\section{KESIMPULAN}

Secara keseluruhannya, kajian ini menguji model hipotesis yang menggabungkan kesejahteraan hidup guru, keserakanan guru, kesejahteraan di tempat kerja dan efikasi guru secara kolektif. Model yang dicadangkan dalam kajian ini dapat menjelaskan hubungan antara kesemua pemboleh ubah yang dikaji dalam konteks guru Maktab Rendah Sains Mara.

Dalam kajian ini kesejahteraan di tempat kerja dipengaruhi dengan kuat oleh keserakanan guru. Kesejahteraan hidup dan keserakanan guru mempengaruhi secara langsung dan tidak langsung efikasi guru secara kolektif. Kesejahteraan di tempat kerja dilihat sebagai satu pemboleh ubah pengantara yang baik dan diingini kerana memberi kesan yang baik terhadap efikasi guru secara kolektif.

Dapatan kajian ini mencadangkan guru perlu lebih peka, menumpukan perhatian dan mengatur rancangan untuk meningkatkan tahap efikasi guru secara kolektif. Pada masa yang sama pentadbir sekolah juga harus merancang dan mengagihkan tugas guru secara adil dan efektif agar guru mempunyai ruang untuk meningkatkan kesejahteraan hidup dan sentiasa mengamalkan keserakanan yang berkesan. Dapatan kajian ini juga telah menyumbang untuk meningkatkan kefahaman dan ilmu terhadap faktor yang mempengaruhi efikasi guru secara 
kolektif serta menyokong teori kognitif sosial. Keseluruhan dapatan kajian ini membuktikan bahawa kesemua pemboleh ubah kajian ini memainkan peranan penting dan menyumbang ke arah peningkatan proses pengajaran dan pembelajaran.

\section{RUJUKAN}

Abdullah, J. (2009). Lowering teacher attrition rates through collegiality. Academic Leadership Journal, 7 (1), 84-88.

Abdul Shukor Shaari, Abd. Rahim Romle \& Mohamad Yazi Yahya.(2006). Bertugas Guru Sekolah Rendah. Kertas yang dibentangkan dalam Seminar Kebangsaan Kepimpinan dan Pengurusan Sekolah, 12-14 Februari. Alson Klana Resort, Seremban.

Ary, D., Jacobs, L. C., \& Razavieh, A. (2002). Introduction to research in education (6th ed.) USA: Wadsworth Group.

Babbie, E. (2007). The practice of social research (11th ed.). Singapore: Thomson Learning.

Baicker, K., Cutler, D., \& Song, Z. (2010). Workplace wellness programs can generate savings. Health Affairs, 29(2), 304-311.

Bajorek, Z. M. (2013). The management of temporary staff in healthcare emergency departments: Implication for patient safety and service quality (Unpublished doctoral dissertation). King's College London: United Kingdom.

Bandura, A. (1977). Self-efficacy: Toward a unifying theory of behavior change. Psychological Review, 84, 191-215.

Bandura, A. ( 1986). Social foundations of thought and actions: A social cognitive theory. Englewood Cliffs, N.J.: Prentice Hall.

Bandura, A. (1993). Perceived self-efficacy in cognitive development and functioning. Educational Psychologist, 28, 117-148.

Bandura, A. (1997). Self-efficacy: Toward a unifying theory behavior change. Psychological Review, 84, 191-215.

Bandura, A. (2006). Adolescent development from an agentic perspective. In F. Pajares, \& T. Urdan (Eds.), ITALIC Self-efficacy beliefs of adolescents (pp.1-43). Greenwich, Connecticut: Information Age Publishing.

Baron, R. M. \& Kenny, D. A. (1986). The moderator-mediator variable distinction in social psychological research: Conceptual, strategic, and statistical considerations. Journal of Personality and Social Psychology, 51, 1173-1182. 
Bentler, P. M. (1990). Comparative fit indexes in strutural models. Psychological Bulletin, 107(2), 238 - 246.

Bolam, R. (2005) Creating and sustaining effective profesional learning communities, Research Report RR637, University of Bristol.

Briner, R., \& Dewberry, C. (2007). Staff wellbeing is key to school success. A research study into the links between staff wellbeing and school performance. London: Worklife Support.

Butt, R. L., \& Retallick, J. (2002) Profesional well being and learning: A study of administrator-teacher workplace relationships. Journal of Educational Enquiry, 3(1), 17-34.

Brislin, R. W. (1970). Back translation for cross-cultural research. Journal of Cross-Cultural Psychology, 1(3), 185-216.

Browne, M. W., \& Cudeck, R. (1993). Structural equation models: Alternative ways of assessing model fit in testing. In K. A. Bollen \& J. S. Long (Eds.). Newbury Park, CA: Sage, 136-62. Caprara, G. V., Barbaranelli, C., Steca, P., \& Malone, P. S. (2006). Teachers' self-efficacy beliefs as determinants of job satisfaction andstudents' academic achievement: A study at the school level. Journal of School Psychology, 44, 473-490.

Day, C. (2000). Leading schools in times of change. Buckingham: Open University Press.

Dewberry, C. \& Briner, R. (2007). Report for Worklife Support on the relation between well-being and climate in schools and pupil performance. London: Worklife Support.

DuFour, R.(2004). What is a professional learning community? Educational Leadership, 61 (8), 6-11.

Eells, R. J.(2011). Meta analysis of the relationship between collective teacher efficacy and student achievement. Dissertations. Paper, 133.

Fuchs, S., \& Edwards, M. R.(2012). Predicting pro-change behaviour the role of perceived organizational justice and organizational identification. Human Resources Management Journal, 22(1),39-59.

Gable, R., Mostert, M., \& Tonelson S. (2004). Assessing professional collaboration in schools: Knowing what works. Preventing Schools Failure, 48 (3), 4-9.

Ghitulescu, B.E. (2013). Making change happen: The impact of work context on adaptive and proactive behaviours. Journal of Applied Behavioral Science 49(2), 206-245. 
Goddard, R. D., Hoy, W. K., \& Woolfolk Hoy, A. (2004). Collective efficacy beliefs: Theoretical developments, empirical evidence, and future directions. Educational Research, 33, 3-13.

Goddard, Y. L., Goddard, R, D., \& Tschannen-moran, M. (2007). A theoretical and empirical investigation of teacher collaboration for school improvement and student achievement in public elementary schools. Teacher Collage Record, 109 (4), 877-896.

Hair, J. F., Black, W. C., Babin, B. J., Anderson, R. E., \& Tatham, R. L.(2006). Multivariate analysis (6th ed.). Upper Saddle River, NJ: Prentice- Hall.

Hallinger, P., \& Heck, R. H. (2010). Collaborative leadership and school improvement: Understanding the impact on school capacity and student learning. School Leadership and Management, 30(2), 95-110.

Hodkinson, P.(2005). Reconceptualising the relations between college-based and workplace learning. Journal of Workplace Learning, 17(8), 521-532.

Idris, A. A., \& Wan Fauziah Wan Yusoff .(2012) Does motivational factor influence organizational commitment and effectiveness?. Journal of Business Management and Economics, 3(1), 1-9.

Jarzabkowski, L. M. (2002). The social dimensions of teacher collegiality. Journal of Educational Enquiry, 3(2), 1-20.

Jewezyn, N. (2010). Job satisfaction, morale, and cultural diversity: Factors influencing workers perspectives, expectations and management strategies. Journal of Virtual Leadership, 1, $1-11$.

Kathryn, P.(2005). The workplace wellbeing index.acqul.dealin. edu.au/instruments.

Kementerian Pelajaran Malaysia (2013). Pelan Pembangunan Pendidikan Malaysia 2013-2025, Kementerian Pelajaran Malaysia.

Klassen, R. M., Bong, M., Usher, E. L., Chong, W. H., Huan, V. S., Wong, I. Y., \& Georgiou, T. (2009). Exploring the validity of the teachers' self-efficacy scale in five countries. Contemporary Educational Psychology,34, 67-76.

Klassen, R. M. (2010). Effects on Teachers' self-efficacy and job satisfaction: Teacher gender, years of experience, and job stress. Journal of Educational Psychology, 102( 3), 741-756. 
Klassen, R. M., Bong, M., Usher, E. L., Chong, W. H., Huan, V. S., Wong, I. Y., \& Georgiou, T. (2009). Exploring the validity of the teachers'self-efficacy scale in five countries. Contemporary Educational Psychology, 34, 67-76.

Knapp, M. S. (2003). Professional development as a policy pathway. Review of Research in Education, 27 (1), 109-157.

Kokkinos, C.M. (2007). Job stressors, personality and burnout in primary school teachers. British Journal of Educational Psychology,77, 229-243.

Krejcie, R.W., \& Morgan, D.W. (1970). Determining sample size for research activities. Educational and Psychological Measurement, 30, 608-619.

Lakey, B., \& Cohen, S. (2000). Social support theory and measurement. In S. Cohen, L.G. Underwood, \& B. H. Gottlieb (Eds.), Social support measurement and intervention: A guide for health and social scientist (pp. 29-52). New York, NY, US: Oxford University Press.

Lean, C.R.,\& Pil, F.K. (2006). Social capital and organizational performance: Evidence from urban public schools. Organization Science, 17 (3), 353-366.

Little, T. D., Cunningham, W. A., Shahar, G., \& Widaman, K. F. (2002). Structural equation modeling: To parcel or not to parcel: Exploring the question, weighting the merits, 9, 151-173.

Little, J. W., Gearhart, M., Curry, M., \& Kafta, J. (2006). Looking at student work for teacher learning, teacher community and school reform. Phi Delta Kappan, 85 (3), 184-192.

Lopez, S.J. (2010). Making ripples: How principals and teachers can spread hope throughout our Schools. Phi Delta Kappan 91, (September 2009), 58-6.

Madiha, S.(2011). The dimensionality of teacher collegiality and the development of teacher collegiality scale. International Journal of Education, 3 (2), 150-222.

Muhyiddin Yaasin (2013). Pelan Pembangunan Pendidikan Malaysia 2013-2025, Kementerian Pelajaran Malaysia.

Nelson, B. (2003). Money is not the root of all motivation. Health Care Registration, 12(10), 7- 9.

Noriati A. Rashid, Boon Pong Ying, \& Wong Kiet Wah (2010). Asas kepimpinan dan perkembangan profesional guru. Shah Alam: Oxford Fajar. 
Numeroff, D. (2005). Teacher collegiality and collaboration in exemplary high school math department (Unpublished doctoral dissertation). Florida Atlantic University, AAT 3162664.

Pas, E., Bradshaw, C., Hershfeldt, P., \& Leaf, P.(2010). A multilevel exploration of the influence of teaher efficacy and burnout on response to student problem behavior and school-based service use. School Psychology Quarterly, 25, 13-27.

Rosna Awang-Hashim \& Azlina Murad Sani (2008). A confirmatory factor analysis of a newly integrated multidimensional school engagement scale. Malaysian Journal of Learning and Instruction, 5, 21- 40.

Rosna, A., O' Neil, H. F., Hocevar, D. (2002). Ethnicity, effort, self-efficacy, worry and statistic achievement in Malaysia: A construct validation of the state-trait motivation model. Educational Assessment, 8, 341 - 364.

Retallick, J., \& Butt. R. (2004). Professional well-being and learning: A study of teacher-peer workplace relationships. Journey of Educational Enquiry, 5 (1), 85-99.

Parmjit, S., Y. F. Chan., \& G. K. Sidhu. (2006). A comprehensive guide to writing a research proposal. Selangor:Venton Publication.

Pas, E., Bradshaw, C., Hershfeldt, P., \& Leaf, P.(2010). A multilevel exploration of the influence of teaher efficacy and burnout on response to student problem behavior and school-based service use. School Psychology Quarterly, 25, 13-27.

Sarwar, S., Aslam, H. D., \& Rasheed, M. I. (2010). Hindering factors of beginning teachers' high performance in higher education Pakistan - A case study of IUB- The Islamia- University of Bahawalpur. International Journal of Education, 2(1), 112-123.

Schaufeli, W. B., \& Salanova, M. (2007). Efficacy or inefficacy, that's the question: Burnout and work engagement, and their relationships with efficacy beliefs. Anxiety, stress, \& coping. An International Journal, 20, 177-196.

Skaalvik, E. M., \& Skaalvik, S. (2007). Dimensions of teacher selfefficacy and relations with strain factors, perceived collective teacher efficacy, and teacher burnout. Journal of Educational Psychology, 99, 611-625.

Skaalvik, E.M., \& Skaalvik, S. (2008). Teacher self-efficacy: Conceptual analysis and relations with teacher burnout and perceived school context. In R. Craven, H.W.Marsh, \& 
D. Mclnerney (Eds.), Self-processes, learning, and enabling human potential (pp.223-247).Connecticut: Information Age Publishing.

Supovitz, J.A., \& Christman, J.B. (2003). Developing communities of instructional practice: Lessons from Cincinnati and Philadelphia. CPRE Policy Briefs, 1-10.

Tabachnik, B.G., \& Fidell, L.S.(2007). Using multivariate statistic (5th ed.) Boston: Pearson Education.

Tatlah, I. A., Ali, Z., \& Saeed, M. (2011). Leadership behavior and organizational commitment: An empirical study of educational profesional. International Journal of Academic Research, 3(2), 1293-1298.

The American Heritage Dictionary of the English language (4th ed.). (2002).

Tengku Faekah Tengku Ariffin, Rosna Awang Hashim \& Khulida Kirana Yahya. (2010). Modelling the relationships between personality factors, perceptions of the school as a learning organisation and workplace learning of school teachers. Malaysian Journal of Learning and Instruction, 7, 16-35.

Trochim, W. M., K., \& Donnelly, J. P.(2008). Research methods knowledge base (3rd ed.). Mason, $\mathrm{OH}$ : Cengage Learning.

Tschnnen-Moran, M. (2001). Collaboration and the need for trust. Journal of Educational Administration, 39 (4), 308-331.

Tschannen - Moran, M., \& Barr, M. (2004). Fostering student learning: The relationship of collective teacher efficacy and student achievement. Leadership and Policy in Schools, 3(3), 189-209.

Tschannen-Moran, M., \& Woolfolk Hoy, A. (2001). Teacher efficacy: Capturing and elusive construct. Teaching and Teacher Education, 17, 783-805.

Tschannen-Moran, M., \& Woolfolk Hoy, A.(2007). The differential antecedents of self-efficacy beliefs of novice and experienced teachers. Teaching and Teacher Education, 23, 944-956.

Van Veen, K., \& Sleegers, P. (2006). How does it feel? Teachers' emotions in a context of change. Journal of Curriculum Studies, 38 (1), 85-111.

Walker, C., \& Greene, B.(2009). The relations between student motivational beliefs and cognitive engagement in high school. Journal of Educational Research, 102, 463-472. 
Wang, J., Odell, S. J., \& Schwille, S. A. (2008). Effects of teacher induction on beginning teachers' teaching: A critical review of the liberature. Journal of Teacher Education, 59 (2), 132-152.

Wiersma, W. (2000), Research in education: An introduction. Boston: Allyn and Bacon.

Williams, A., Prestage, S., \& Bedward, J. (2001). Individualism to collaboration: The significance of teacher culture to the induction of newly qualified teachers. Journal of Education for Teaching, 27 (3), 253-267.

Woods, A. M., \& Weasmer, J. (2002). Maintaining job satisfaction: Engaging professionals as active participants. The Clearing House, 75(4), 186-189.

Woolfolk Hoy, A., \& Spero, R. B. (2005). Changes in teacher efficacy during the early years of teaching: A comparison of four measures. Teaching and Teacher Education, 21, 343-356.

Xiaofu, P., \& Qiwen, Q. (2007). An analysis of the relation between secondary school organizational elimate and teacher job satisfaction. Chinese Education and Society, 40 (5), 65-77.

Yong Z., \& Yue, Y. (2007). Causes for burnout among secondary and elementary school teachers and preventive strategies. Chinese Education and Society, 40 (5), 78-85.

Yoon, K. S., Duncan, T., Lee, S.W.Y., Scarloss, B., \& Shapley, K. (2007). Reviewing the evidence on how teacher professional development affects students achievement (Issues \& Answers Report, REL 2007-No.033).

Zainudin, A.( 2012). Structural equation modelling using Amos graphic. Shah Alam: Universiti Teknologi MARA Publication Centre (UiTM Press). 